\title{
Are There Age-Related Differences in the In-Hospital Treatment of Victims from Out-of-Hospital Cardiac Arrest?
}

\author{
Martin Christ, Katharina Isabel von Auenmueller, Irini Maria Breker, Jeanette Liebeton, \\ Michael Brand, Jan Peter Noelke, Hans-Joachim Trappe \\ Department of Cardiology and Angiology, Ruhr-University Bochum, Bochum, Germany \\ Email: martin.christ@marienhospital-herne.de
}

Received 22 May 2015; accepted 23 June 2015; published 26 June 2015

Copyright (C) 2015 by authors and Scientific Research Publishing Inc.

This work is licensed under the Creative Commons Attribution International License (CC BY).

http://creativecommons.org/licenses/by/4.0/

(c) (i) Open Access

\begin{abstract}
Objective: Hardly anything is known about reasons for age-related differences in surviving outof-hospital cardiac arrest (OHCA) with worse surviving rates in elderly. Methods: 204 victims from OHCA who were admitted in our hospital between January $1^{\text {st }} 2008$ and December $31^{\text {st }} 2013$ were identified. According to their mean age $(69.1 \pm 14.2$ years $)$ we classified those patients (pts) who were younger than mean age minus standard deviation (SD) as young, and those victims from OHCA who were older than mean age plus SD as old. Results: Young victims from OHCA ( $\mathrm{n}=32 \mathrm{pts}$ ) presented more often with an initial shockable rhythm than the elderly ( $n=38$ pts) $(50.0 \%$ vs. $21.1 \% ; p=0.014)$, received more often coronary angiography $(71.9 \%$ vs. $18.4 \% ; p<0.001)$, more often percutaneous coronary intervention $(46.9 \%$ vs. $13.2 \%$; $p=0.003)$, more often mild therapeutic hypothermia $(78.1 \%$ vs. $15.8 \%$; $p<0.001)$ and could be more often discharged alive $(65.6 \%$ vs. $21.1 \%$; $p$ <.001). Conclusion: At hospital admission, physiological data did not differ between young and old victims from OHCA. Less use of coronary angiography and mild therapeutic hypothermia in elderly victims from OHCA might suggest that the observed age-related differences in survival following OHCA might be caused by age-related differences in the in-hospital treatment.
\end{abstract}

\section{Keywords}

Out-of-Hospital Cardiac Arrest, Mild Therapeutic Hypothermia, Coronary Angiography, Resuscitation, Elderly

\section{Introduction}

Witnessed arrest [1] [2], bystander-initiated resuscitation [2] [3], initial shockable rhythm [2] [4], shorter dura-

How to cite this paper: Christ, M., von Auenmueller, K.I., Breker, I.M., Liebeton, J., Brand, M., Noelke, J.P. and Trappe, H.-J. (2015) Are There Age-Related Differences in the In-Hospital Treatment of Victims from Out-of-Hospital Cardiac Arrest? International Journal of Clinical Medicine, 6, 431-438. http://dx.doi.org/10.4236/ijcm.2015.66056 
tion of resuscitation [5] and also younger age [6]-[11] have been repetitively described as advantages in surviving out-of-hospital cardiac arrest (OHCA).

However, while the advantage of the most above-mentioned factors can be explained by their positive effect on shortening the no-flow time, hardly anything is known about specific reasons for the age-related differences in surviving OHCA with worse surviving rates in the elderly. We therefore initiated this study to learn more about the differences in the post cardiac arrest treatment of very old and very young patients.

\section{Methods}

\subsection{Patients}

Altogether, 204 patients with a mean age of $69.1 \pm 14.2$ years [range 18 - 97 years] were admitted to our hospital between January $1^{\text {st }} 2008$ and December $31^{\text {st }} 2013$ following OHCA.

According to the mean age we classified those patients who were younger than mean age minus standard deviation (SD) as young, and those victims from OHCA who were older than mean age plus SD as old.

\subsection{Data Analysis}

Patients data were collected from the individual patient `s health records and anonymous stored on a central data base. Statistical analysis was performed with the Statistical Package of Social Science (SPSS 22.0, IBM, Armonk, NY, USA). Continuous variables are expressed as the mean \pm SD, comparisons of categorical variables among groups were conducted using Chi-square tests or student's t-test.

Data collection and analysis was approved by the local ethical review committee.

\section{Results}

\subsection{Young Victims from OHCA}

32 victims from OHCA (19 male (59.4\%) and 13 female (40.6\%)) were classified as young and had a mean age of $46.7 \pm 9.3$ years. There were 25 witnessed arrests (78.1\%) in this group, 21 patients received bystander-initiated resuscitation (65.6\%) and 16 patients (50.0\%) presented with an initial shockable rhythm.

At admission, first body temperature was $35.3^{\circ} \mathrm{C} \pm 1.4^{\circ} \mathrm{C}$ (degree Celsius), first $\mathrm{pH} 7.15 \pm 0.25$, first $\mathrm{pO}_{2}$ $203.2 \pm 167.1 \mathrm{mmHg}$, first $\mathrm{pCO}_{2} 53.0 \pm 26.1 \mathrm{mmHg}$, first lactate $11.9 \pm 18.4 \mathrm{mmol} / \mathrm{l}$.

11 patients (34.4\%) presented with myocardial infarction (8 ST elevation myocardial infarction (STEMI) (25.0\%) (3 non-ST elevation myocardial infarction (NSTEMI) (9.4\%)). Creatine kinase was $373.4 \pm 540.4$ U/l and troponin I $2.3 \pm 9.4 \mathrm{ng} / \mathrm{ml}$ at admission. 23 patients (71.9\%) received coronary angiography, 15 (46.9\%) percutaneous coronary intervention (PCI). 25 patients (78.1\%) were treated with mild therapeutic hypothermia (MTH), 21 (65.6\%) could be discharged alive.

\subsection{Old Victims from OHCA}

38 victims from OHCA (14 male (36.8\%) and 24 female (73.2\%)) were classified as old and had a mean age of $87.2 \pm 3.4$ years. There were 23 witnessed arrests (60.5\%) in this group, 21 patients received bystander-initiated resuscitation (55.3\%) and 8 patients (21.1\%) presented with an initial shockable rhythm.

At admission, first body temperature was $35.2^{\circ} \mathrm{C} \pm 1.4^{\circ} \mathrm{C}$, first $\mathrm{pH} 7.14 \pm 0.20$, first $\mathrm{pO}_{2} 193.1 \pm 162.5 \mathrm{mmHg}$, first $\mathrm{pCO}_{2} 50.7 \pm 21.8 \mathrm{mmHg}$, first lactate $8.0 \pm 4.3 \mathrm{mmol} / \mathrm{l}$.

8 patients (21.1\%) presented with myocardial infarction (3 STEMI (7.9\%), 5 NSTEMI (13.2\%)). Creatine kinase was $291.2 \pm 535.2 \mathrm{U} / \mathrm{l}$ and Troponin I $2.6 \pm 8.8 \mathrm{ng} / \mathrm{ml}$ at admission. 7 patients (18.4\%) received coronary angiography, 5 (13.2\%) PCI. 6 patients (15.8\%) were treated with MTH, 8 (21.1\%) could be discharged alive.

\subsection{Comparison of Old and Young Victims from OHCA}

Young victims from OHCA presented more often with an initial shockable rhythm than elderly $(\mathrm{p}=0.014)$, received more often coronary angiography $(\mathrm{p}<0.001)$, more often PCI $(\mathrm{p}=0.003)$, more often MTH $(\mathrm{p}<0.001)$ and could be more often discharged alive $(\mathrm{p}<0.001)$. All data are summarized in Table 1 . 
Table 1. Patient's characteristics of young and old victims from OHCA.

\begin{tabular}{|c|c|c|c|}
\hline & Young $(\mathrm{n}=32)$ & Old $(n=38)$ & $\mathrm{p}$ \\
\hline Male & $19(59.4 \%)$ & $14(36.8 \%)$ & 0.060 \\
\hline Age (years) & $46.7 \pm 9.3$ & $87.2 \pm 3.4$ & $<0.001$ \\
\hline Witnessed arrest & 25 (78.1\%) & $23(60.5 \%)$ & 0.077 \\
\hline Bystander-initiated resuscitation & $21(65.6 \%)$ & $21(55.3 \%)$ & 0.347 \\
\hline Initial shockable rhythm & $16(50.0 \%)$ & $8(21.1 \%)$ & 0.014 \\
\hline First body temperature $\left({ }^{\circ} \mathrm{C}\right)$ & $35.3 \pm 1.4$ & $35.2 \pm 1.4$ & 0.992 \\
\hline First $\mathrm{pH}$ & $7.15 \pm 0.25$ & $7.14 \pm 0.20$ & 0.688 \\
\hline First $\mathrm{pO}_{2}(\mathrm{mmHg})$ & $203.2 \pm 167.1$ & $193.1 \pm 162.5$ & 0.925 \\
\hline First $\mathrm{pCO}_{2}(\mathrm{mmHg})$ & $53.0 \pm 26.1$ & $50.7 \pm 21.8$ & 0.468 \\
\hline First lactate (mmol/l) & $11.9 \pm 18.4$ & $8.0 \pm 4.3$ & 0.117 \\
\hline Creatine kinase (CK) (U/l) & $373.4 \pm 540.4$ & $291.2 \pm 535.2$ & 0.653 \\
\hline Troponin I (ng/ml) & $2.3 \pm 9.4$ & $2.6 \pm 8.8$ & 0.865 \\
\hline Myocardial infarction & $11(34.4 \%)$ & $8(21.1 \%)$ & \\
\hline STEMI & $8(25.0 \%)$ & $3(7.9 \%)$ & 0.581 \\
\hline NSTEMI & $3(9.4 \%)$ & $5(13.2 \%)$ & \\
\hline Coronary angiography & 23 (71.9\%) & 7 (18.4\%) & $<0.001$ \\
\hline Percutaneous coronary intervention & 15 (46.9\%) & $5(13.2 \%)$ & 0.003 \\
\hline Mild therapeutic hypothermia & $25(78.1 \%)$ & $6(15.8 \%)$ & $<\mathbf{0 . 0 0 1}$ \\
\hline Discharged alive & $21(65.6 \%)$ & $8(21.1 \%)$ & $<0.001$ \\
\hline
\end{tabular}

STEMI: ST elevation myocardial infarction; NSTEMI: non ST elevation myocardial infarction.

\subsection{In-Hospital Treatment Stratified by the Initial Findings of Myocardial Infarction or Shockable Rhythm}

$100.0 \%$ of the young patients who fulfilled the criteria of STEMI [12], 33.3\% of the young patients who fulfilled the criteria of NSTEMI [13] and 57.1\% of the young patients without myocardial infarction received coronary angiography.

In elderly, 33.3\% of the patients with STEMI, $40.0 \%$ of the patients with NSTEMI and $13.3 \%$ of the patients without myocardial infarction received coronary angiography (Table 2, Figure 1).

Mild therapeutic hypothermia was applied in $93.8 \%$ of the young patient with initial shockable rhythm and $68.8 \%$ of the young patients without initial shockable rhythm. In elderly, MTH was used in 37.5\% of the patients with initial shockable rhythm and $10.0 \%$ of the patients without initial shockable rhythm (Table 2, Figure 2).

\section{Discussion}

Our data are in line with previously published studies that described better surviving rates in younger than in elderly victims from OHCA (Table 1) [6]-[11]. Possible reasons for these differences might be estimated in the pre-hospital but also the intra-hospital findings.

\subsection{Pre-Hospital Findings}

It has been argued that a presumably higher rate of nursing home residencies in the elderly patients might influence survival from OHCA. Of course, the most common incident locations of cardiac arrest are either the 


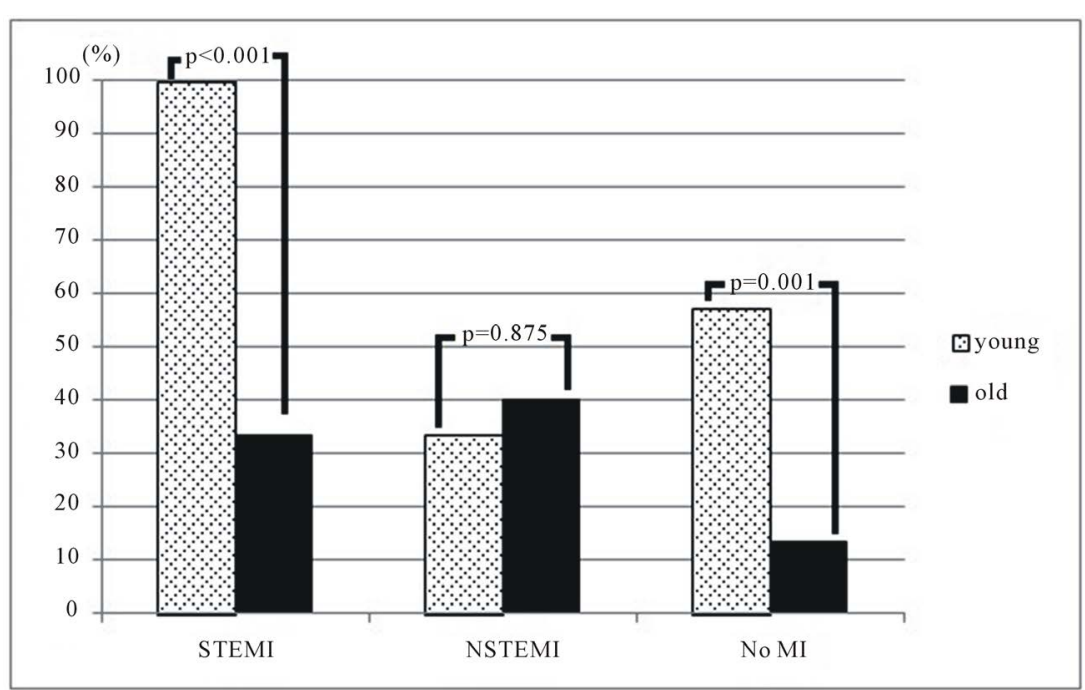

Figure 1. Percentage of the old and young patients who received coronary angiography following OHCA depending on their initial presentation with myocardial infarction or not.

Table 2. Coronary angiography and application of mild therapeutic hypothermia in old and young victims from OHCA depending on first laboratory and electrocardiographic findings.

\begin{tabular}{ccc}
\hline$\underline{\text { STEMI }}$ & Young $(\mathrm{n}=32)$ & Old $(\mathrm{n}=38)$ \\
Coronary angiography & 8 & 3 \\
No coronary angiography & $8(100.0 \%)$ & $1(33.3 \%)$ \\
NSTEMI & $0(0.0 \%)$ & $2(66.6 \%)$ \\
Coronary angiography & 3 & 5 \\
No coronary angiography & $1(33.3 \%)$ & $2(40.0 \%)$ \\
No myocardial infarction & $2(66.6 \%)$ & $3(60.0 \%)$ \\
Coronary angiography & 21 & 30 \\
No coronary angiography & $12(57.1 \%)$ & $4(13.3 \%)$ \\
Initial shockable rhythm & $9(42.9 \%)$ & $26(86.7 \%)$ \\
Mild therapeutic hypothermia & 16 & $3(37.5 \%)$ \\
No mild therapeutic hypothermia & $15(93.8 \%)$ & $5(62.5 \%)$ \\
Initial non-shockable rhythm & $1(6.2 \%)$ & 30 \\
Mild therapeutic hypothermia & 16 & $3(10.0 \%)$ \\
No mild therapeutic hypothermia & $11(68.8 \%)$ & $27(90.0 \%)$
\end{tabular}

STEMI: ST elevation myocardial infarction; NSTEMI: non ST elevation myocardial infarction.

patient's home or-especially in elderly—-the nursing homes [14] [15]. However, by now, there are discrepant findings about the influence of nursing home residencies on patient's survival following OHCA; some authors reported a predictive value of nursing home residency for decreased survival to discharge following OHCA [16]-[18] whereas there were similar survival rates in another study [19].

The findings of the present study cannot support the theory of a relevant influence of nursing home residencies on patient's survival. In fact, there was just one difference between young and old victims from OHCA in the pre-hospital setting: a lower rate of initial shockable rhythm in elderly (Table 1) [20]-[22]. 


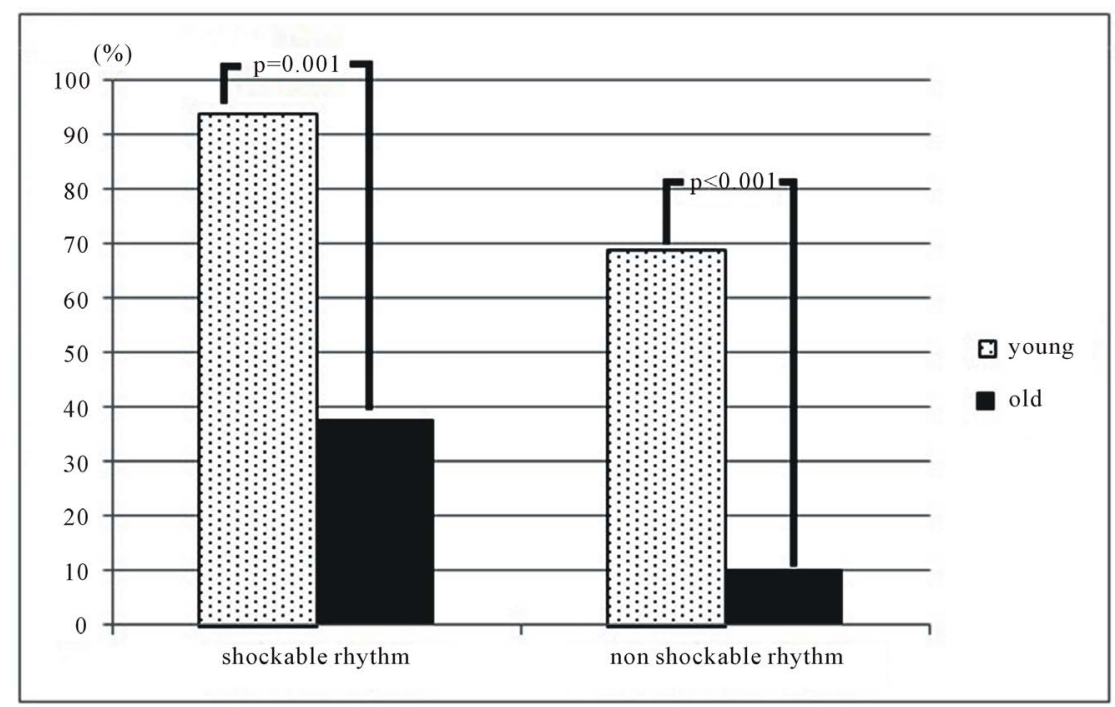

Figure 2. Percentage of the old and young patients who were treated with mild therapeutic hypothermia following OHCA depending on whether they initially present with a shockable rhythm.

Physiological data, such as first $\mathrm{pH}$, first $\mathrm{pO}_{2}$, first $\mathrm{pCO}_{2}$, first lactate and the initial body temperature were all similar in young and old victims from OHCA (Table 1).

\subsection{In-Hospital Findings}

The current guidelines for the management of patients following OHCA recommend two main techniques in the post-resuscitation treatment: mild therapeutic hypothermia and early coronary angiography—at least in patients with suspected cardiac cause of death [23]. The combination of mild therapeutic hypothermia (MTH) and early coronary angiography—inclusive PCI if necessary—is feasible and safe [11] [24]-[27] and has been shown to improve surviving rates from OHCA [7] [28] [29].

However, in our data, only $18.4 \%$ of the elderly patients received coronary angiography and only $15.8 \%$ were treated with MTH whereas we observed a broad use of both techniques in young patients (Table 1).

It might be hypothesized, that a higher prevalence of severe comorbidities in elderly patients contradicts invasive techniques but to our knowledge, there are no studies that really record either the pre-arrest comorbidities or the functional status of victims from OHCA and clarify their influence on survival, neither in the victims from OHCA in general, nor in elderly in particular. Furthermore, previous studies confirmed that the use of mild therapeutic hypothermia is safe [11] [30], complicative infections during therapeutic hypothermia do not impact mortality or neurological recovery [31] and a limitation of post-resuscitation MTH based on age alone is not justified [32].

Taking into account that especially the early induction of MTH during cardiac arrest improves neurological outcomes [33], we doubt that relevant differences in the patient`s advance directives caused the rare use of MTH or coronary angiography in elderly.

At last, it might be discussed that a lower rate of an initial shockable rhythm in old patients (Table 1) led to lower application rates of MTH in elderly as the current guidelines recommend the use of MTH in patients with an initial shockable rhythm [23].

However, subgroup analysis yielded that the application of mild therapeutic hypothermia was also rare in elderly with an initial shockable rhythm (Table 2, Figure 2) and also coronary angiography was infrequently used in elderly patients, even in those who presented with STEMI following OHCA (Table 2, Figure 2).

Therefore, in summary, we interpret our data as an expression of age-related differences in the post-resuscitation treatment with a worse therapy in elderly.

Of course, this is a single center study and our findings must be confirmed in further investigations but our data are also in line with further descriptions of less commitment on the treatment of old patients; an obviously frequent finding in cardiovascular disease. For example, there was a rare secondary cardiovascular preventive 
therapy in elderly [34] an undertreatment with oral anticoagulation [35] [36], the finding that advancing age was inversely associated with receipt of evidence-based cardiac therapies following acute myocardial infarction [37] and the observation that elderly patients were less likely to receive evidence-based treatments in heart failure [38].

\subsection{Limitations}

The present study is a single center study and we did not adjust for confounding factors, but however, the characteristics of our patient's are comparable to those described previously in other studies [11] [24] [28] and the observation of less commitment on the treatment of old patients was frequent in diverse other cardiovascular disease [34]-[38]. However, further investigations should verify our data.

\section{Conclusions}

In summary, our data suggest that age-related differences in survival following OHCA might be caused by agerelated differences in the in-hospital treatment.

Expecting an increasing number of elderly victims from OHCA during the next years, we see the need for further studies with larger sample sizes to confirm our findings.

\section{Conflict of Interest}

All authors declare: no conflict of interest.

\section{References}

[1] Buntaine, A.J., Dangerfield, C., Pulikottil, T., Katz, L.M., Cook, A.M., Reed, B.N. and Katz, J.N. (2014) Putting Class IIb Recommendations to the Test: The Influence of Unwitnessed and Non-VT/VF Arrests on Resource Consumption and Outcomes in Therapeutic Hypothermia and Targeted Temperature Management. Critical Pathways in Cardiology, 13, 78-81. http://dx.doi.org/10.1097/hpc.0000000000000011

[2] Sasson, C., Rogers, M.A., Dahl, J. and Kellermann, A.L. (2010) Predictors of Survival from Out-of-Hospital Cardiac Arrest: A Systematic Review and Meta-Analysis. Circulation Cardiovascular Quality and Outcomes, 3, 63-81. http://dx.doi.org/10.1161/CIRCOUTCOMES.109.889576

[3] Kitamura, T., Morita, S., Kiyohara, K., Nishiyama, C., Kajino, K., Sakai, T., Nishiuchi, T., Hayashi, Y., Shimazu, T., Iwami, T. and Utstein Osaka Project (2014) Trends in Survival among Elderly Patients with Out-of-Hospital Cardiac Arrest: A Prospective, Population-Based Observation from 1999 to 2011 in Osaka. Resuscitation, 85, 1432-1438. http://dx.doi.org/10.1016/j.resuscitation.2014.07.017

[4] Grimaldi, D., Dumas, F., Perier, M.C., Charpentier, J., Varenne, O., Zuber, B., Vivien, B., Pène, F., Empana, J.P. and Cariou, A. (2014) Short- and Long-Term Outcome in Elderly Patients after Out-of-Hospital Cardiac Arrest: A Cohort Study. Critical Care Medicine, 42, 2350-2357. http://dx.doi.org/10.1097/CCM.0000000000000512

[5] Kim, W.Y., Giberson, T.A., Uber, A., Berg, K., Cocchi, M.N. and Donnino, M.W. (2014) Neurologic Outcome in Comatose Patients Resuscitated from Out-of-Hospital Cardiac Arrest with Prolonged Downtime and Treated with Therapeutic Hypothermia. Resuscitation, 85, 1042-1046. http://dx.doi.org/10.1016/j.resuscitation.2014.04.005

[6] Ballesteros-Peña, S., Abecia-Inchaurregui, L.C. and Echevarría-Orella, E. (2013) Factors Associated with Mortality in Out-of-Hospital Cardiac Arrests Attended in Basic Life Support Units in the Basque Country (Spain). Revista Española de Cardiología (English Edition), 66, 269-274. http://dx.doi.org/10.1016/j.rec.2012.09.014

[7] Forslund, A.S., Söderberg, S., Jansson, J.H. and Lundblad, D. (2013) Trends in Incidence and Outcome of Out-ofHospital Cardiac Arrest among People with Validated Myocardial Infarction. European Journal of Preventive Cardiology, 20, 260-267. http://dx.doi.org/10.1177/1741826711432032

[8] Fothergill, R.T., Watson, L.R., Virdi, G.K., Moore, F.P. and Whitbread, M. (2014) Survival of Resuscitated Cardiac Arrest Patients with ST-Elevation Myocardial Infarction (STEMI) Conveyed Directly to a Heart Attack Centre by Ambulance Clinicians. Resuscitation, 85, 96-98. http://dx.doi.org/10.1016/j.resuscitation.2013.09.010

[9] Bunch, T.J., West, C.P., Packer, D.L., Panutich, M.S. and White, R.D. (2004) Admission Predictors of In-Hospital Mortality and Subsequent Long-Term Outcome in Survivors of Ventricular Fibrillation Out-of-Hospital Cardiac Arrest: A Population-Based Study. Cardiology, 102, 41-47. http://dx.doi.org/10.1159/000077003

[10] Pleskot, M., Hazukova, R., Stritecka, H. and Cermakova, E. (2011) Five-Year Survival of Patients after Out-of-Hospital Cardiac Arrest Depending on Age. Archives of Gerontology and Geriatrics, 53, e88-e92.

http://dx.doi.org/10.1016/j.archger.2010.06.021 
[11] Nielsen, N., Hovdenes, J., Nilsson, F., Rubertsson, S., Stammet, P., Sunde, K., Valsson, F., Wanscher, M., Friberg, H. and Hypothermia Network (2009) Outcome, Timing and Adverse Events in Therapeutic Hypothermia after Out-ofHospital Cardiac Arrest. Acta Anaesthesiologica Scandinavica, 53, 926-934.

http://dx.doi.org/10.1111/j.1399-6576.2009.02021.x

[12] Task Force on the Management of ST-Segment Elevation Acute Myocardial Infarction of the European Society of Cardiology (ESC), Steg, P.G., James, S.K., Atar, D., Badano, L.P., Blömstrom-Lundqvist, C., Borger, M.A., Di Mario, C., Dickstein, K., Ducrocq, G., Fernandez-Aviles, F., Gershlick, A.H., Giannuzzi, P., Halvorsen, S., Huber, K., Juni, P., Kastrati, A., Knuuti, J., Lenzen, M.J., Mahaffey, K.W., Valgimigli, M., van’t Hof, A., Widimsky, P. and Zahger, D. (2012) ESC Guidelines for the Management of Acute Myocardial Infarction in Patients Presenting with ST-Segment Elevation. European Heart Journal, 33, 2569-2619.

[13] Hamm, C.W., Bassand, J.P., Agewall, S., Bax, J., Boersma, E., Bueno, H., Caso, P., Dudek, D., Gielen, S., Huber, K., Ohman, M., Petrie, M.C., Sonntag, F., Uva, M.S., Storey, R.F., Wijns, W., Zahger, D. and ESC Committee for Practice Guidelines (2011) ESC Guidelines for the Management of Acute Coronary Syndromes in Patients Presenting without Persistent ST-Segment Elevation: The Task Force for the Management of Acute Coronary Syndromes (ACS) in Patients Presenting without Persistent ST-Segment Elevation of the European Society of Cardiology (ESC). European Heart Journal, 32, 2999-3054. http://dx.doi.org/10.1093/eurheartj/ehr236

[14] Christ, M., von Auenmüller, K.I., Grett, M., Dierschke, W. and Trappe, H.J. (2014) [Who Observes Out-of-Hospital Cardiac Arrest in Germany]? Deutsche Medizinische Wochenschrift, 139, 2225-2230. http://dx.doi.org/10.1055/s-0034-1387296

[15] Horsted, T.I., Rasmussen, L.S., Lippert, F.K. and Nielsen, S.L. (2004) Outcome of Out-of-Hospital Cardiac Arrest-Why Do Physicians Withhold Resuscitation Attempts? Resuscitation, 63, 287-293. http://dx.doi.org/10.1016/j.resuscitation.2004.05.005

[16] Iwami, T., Hiraide, A., Nakanishi, N., Hayashi, Y., Nishiuchi, T., Uejima, T., Morita, H., Shigemoto, T., Ikeuchi, H., Matsusaka, M., Shinya, H., Yukioka, H. and Sugimoto, H. (2006) Outcome and Characteristics of Out-of-Hospital Cardiac Arrest According to Location of Arrest: A Report from a Large-Scale, Population-Based Study in Osaka, Japan. Resuscitation, 13, 221-228. http://dx.doi.org/10.1016/j.resuscitation.2005.08.018

[17] Kim, C., Becker, L. and Eisenberg, M.S. (2000) Out-of-Hospital Cardiac Arrest in Octogenarians and Nonagenarians. Archives of Internal Medicine, 13, 3439-3443. http://dx.doi.org/10.1001/archinte.160.22.3439

[18] Deasy, C., Bray, J.E., Smith, K., Harriss, L.R., Bernard, S.A. and Cameron, P. (2011) Out-of-Hospital Cardiac Arrests in the Older Age Groups in Melbourne, Australia. Resuscitation, 13, 398-403. http://dx.doi.org/10.1016/j.resuscitation.2010.12.016

[19] Søholm, H., Bro-Jeppesen, J., Lippert, F.K., Køber, L., Wanscher, M., Kjaergaard, J. and Hassager, C. (2014) Resuscitation of Patients Suffering from Sudden Cardiac Arrests in Nursing Homes Is not Futile. Resuscitation, 85, 369-375. http://dx.doi.org/10.1016/j.resuscitation.2013.10.033

[20] Swor, R.A., Jackson, R.E., Tintinalli, J.E. and Pirrallo, R.G. (2000) Does Advanced Age Matter in Outcomes after Out-of-Hospital Cardiac Arrest in Community-Dwelling Adults? Academic Emergency Medicine, 7, 762-768. http://dx.doi.org/10.1111/j.1553-2712.2000.tb02266.x

[21] Bonnin, M.J., Pepe, P.E. and Clark, P.S. (1993) Survival in the Elderly after Out-of-Hospital Cardiac Arrest. Critical Care Medicine, 21, 1645-1651. http://dx.doi.org/10.1097/00003246-199311000-00012

[22] Van Hoeyweghen, R.J., Bossaert, L.L., Mullie, A., Martens, P., Delooz, H.H., Buylaert, W.A., Calle, P.A., Corne, L. (1992) Survival after Out-of-Hospital Cardiac Arrest in Elderly Patients. Annals of Emergency Medicine, 21, 11791184. http://dx.doi.org/10.1016/S0196-0644(05)81742-1

[23] Nolan, J.P., Soar, J., Zideman, D.A., Biarent, D., Bossaert, L.L., Deakin, C., Koster, R.W., Wyllie, J., Böttiger, B. and ERC Guidelines Writing Group (2010) European Resuscitation Council Guidelines for Resuscitation 2010 Section 1. Executive Summary. Resuscitation, 81, 1219-1276. http://dx.doi.org/10.1016/j.resuscitation.2010.08.021

[24] Sunde, K., Pytte, M., Jacobsen, D., Mangschau, A., Jensen, L.P., Smedsrud, C., Draegni, T. and Steen, P.A. (2007) Implementation of a Standardised Treatment Protocol for Post Resuscitation Care after Out-of-Hospital Cardiac Arrest. Resuscitation, 73, 29-39. http://dx.doi.org/10.1016/j.resuscitation.2006.08.016

[25] Knafelj, R., Radsel, P., Ploj, T. and Noc, M. (2007) Primary Percutaneous Coronary Intervention and Mild Induced Hypothermia in Comatose Survivors of Ventricular Fibrillation with ST-Elevation Acute Myocardial Infarction. Resuscitation, 74, 227-234. http://dx.doi.org/10.1016/j.resuscitation.2007.01.016

[26] Hovdenes, J., Laake, J.H., Aaberge, L., Haugaa, H. and Bugge, J.F. (2007) Therapeutic Hypothermia after Out-of-HosPital Cardiac Arrest: Experiences with Patients Treated with Percutaneous Coronary Intervention and Cardiogenic Shock. Acta Anaesthesiologica Scandinavica, 51, 137-142. http://dx.doi.org/10.1111/j.1399-6576.2006.01209.x

[27] Wolfrum, S., Pierau, C., Radke, P.W., Schunkert, H. and Kurowski, V. (2008) Mild Therapeutic Hypothermia in Patients after Out-of-Hospital Cardiac Arrest Due to Acute ST Segment Elevation Myocardial Infarction Undergoing 
Immediate Percutaneous Coronary Intervention. Critical Care Medicine, 36, 1780-1786.

http://dx.doi.org/10.1097/CCM.0b013e31817437ca

[28] Stub, D., Hengel, C., Chan, W., Jackson, D., Sanders, K., Dart, A.M., Hilton, A., Pellegrino, V., Shaw, J.A., Duffy, S.J., Bernard, S. and Kaye, D.M. (2011) Usefulness of Cooling and Coronary Catheterization to Improve Survival in Outof-Hospital Cardiac Arrest. American Journal of Cardiology, 107, 522-527. http://dx.doi.org/10.1016/j.amjcard.2010.10.011

[29] Kocjancic, S.T., Jazbec, A. and Noc, M. (2014) Impact of Intensified Postresuscitation Treatment on Outcome of Comatose Survivors of Out-of-Hospital Cardiac Arrest According to Initial Rhythm. Resuscitation, 85, 1364-1369. http://dx.doi.org/10.1016/j.resuscitation.2014.06.028

[30] Bernard, S. (2009) Hypothermia after Cardiac Arrest: Expanding the Therapeutic Scope. Critical Care Medicine, 37, 227-233. http://dx.doi.org/10.1097/CCM.0b013e3181aa5d0c

[31] Kuchena, A., Merkel, M.J. and Hutchens, M.P. (2014) Post Cardiac Arrest Temperature Management: Infectious Risks. Current Opinion in Critical Care, 20, 507-515. http://dx.doi.org/10.1097/MCC.0000000000000125

[32] Busch, M. and Søreide, E. (2011) Should Advanced Age Be a Limiting Factor in Providing Therapeutic Hypothermia to Cardiac Arrest Survivors? A Single-Center Observational Study. Therapeutic Hypothermia and Temperature Management, 1, 29-32. http://dx.doi.org/10.1089/ther.2010.0006

[33] Nagao, K., Kikushima, K., Watanabe, K., Tachibana, E., Tominaga, Y., Tada, K., Ishii, M., Chiba, N., Kasai, A., Soga, T., Matsuzaki, M., Nishikawa, K., Tateda, Y., Ikeda, H. and Yagi, T. (2010) Early Induction of Hypothermia during Cardiac Arrest Improves Neurological Outcomes in Patients with Out-of-Hospital Cardiac Arrest Who Undergo Emergency Cardiopulmonary Bypass and Percutaneous Coronary Intervention. Circulation Journal, 74, 77-85. http://dx.doi.org/10.1253/circj.CJ-09-0502

[34] Labuz-Roszak, B., Skrzypek, M., Pierzchała, K., Machowska-Majchrzak, A., Mossakowska, M., Chudek, J., MańkaGaca, I., Bartman, W. and Więcek, A. (2014) Secondary Prevention of Stroke in Elderly People in Poland-Results of PolSenior Study. Neurologia i Neurochirurgia Polska, 48, 85-90. http://dx.doi.org/10.1016/j.pjnns.2013.11.001

[35] Lip, G.Y., Laroche, C., Dan, G.A., Santini, M., Kalarus, Z., Rasmussen, L.H., Ioachim, P.M., Tica, O., Boriani, G., Cimaglia, P., Diemberger, I., Hellum, C.F., Mortensen, B. and Maggioni, A.P. (2014) "Real-World" Antithrombotic Treatment in Atrial Fibrillation: The EORP-AF Pilot Survey. The American Journal of Medicine, 127, 519-529. http://dx.doi.org/10.1016/j.amjmed.2013.12.022

[36] Gao, W.Q., Guo, Y.T., Ma, J.L., Zhu, P. and Wang, Y.T. (2014) Analysis of Antithrombotic Therapy in Elderly Patients with Atrial Fibrillation. Genetics and Molecular Research, 13, 736-743. http://dx.doi.org/10.4238/2014.January.29.4

[37] Chen, H.Y., McManus, D.D., Saczynski, J.S., Gurwitz, J.H., Gore, J.M., Yarzebski, J. and Goldberg, R.J. (2014) Characteristics, Treatment Practices, and In-Hospital Outcomes of Older Adults Hospitalized with Acute Myocardial Infarction. Journal of the American Geriatrics Society, 62, 1451-1459. http://dx.doi.org/10.1111/jgs.12941

[38] Pulignano, G., Del Sindaco, D., Tavazzi, L., Lucci, D., Gorini, M., Leggio, F., Porcu, M., Scherillo, M., Opasich, C., Di Lenarda, A., Senni, M., Maggioni, A.P. and IN-CHF Investigators (2002) Clinical Features and Outcomes of Elderly Outpatients with Heart Failure Followed up in Hospital Cardiology Units: Data from a Large Nationwide Cardiology Database (IN-CHF Registry). American Heart Journal, 143, 45-55. http://dx.doi.org/10.1067/mhj.2002.119608 